\title{
An improved radial point interpolation method applied for elastic problem with functionally graded material
}

- Phung Quoc Viet

- Nguyen Thanh Nha

- Truong Tich Thien

Ho Chi Minh city University of Technology, VNU-HCM

(Manuscript Received on August 01 ${ }^{\text {st }}$, 2015, Manuscript Revised August 27 ${ }^{\text {th }}$, 2015)

\section{ABSTRACT:}

A meshless method based on radial point interpolation was developed as an effective tool for solving partial differential equations, and has been widely applied to a number of different problems. Besides its advantages, in this paper we introduce a new way to improve the speed and time calculations, by construction and evaluation the support domain. From the analysis of

Keywords: Meshless Method, Radial Basis Function, Radial Point Interpolation, FGM

\section{INTRODUCTION}

In recent years, meshless methods have been widely used to solve partial differential equations (PDEs), Element Method free Galerkin (EFG) proposed by Belytschko [1], this method allows the construction of technical shape functions by approximately moving least squares (MSL) [2], which does not require the connection between the nodes to build the interpolation function in the distribution contemplated [3]. The interpolation method through the center point (RPIM) [4] is an approach that is important for the grid boundary value problem. This method was applied to analyze reliability for a variety of $2 \mathrm{D}$ and $3 \mathrm{D}$ Solids, The formulation is based on the shape functions a system interpolation points, each point interpolation built up an independent shape two-dimensional thin plates with different profiles, structured conventional isotropic materials and functional graded materials (FGM), the results are compared with the results had done before that indicates: on the one hand shows the accuracy when using the new way, on the other hand shows the time count as more economical.

functions, this job is simple but yet in the process of building the shape functions of the system contemplated node will vary depending on the position of the interpolation point, so it will take more time. In this article we use RPIM to define support domain to save time, corporeality:

Set the child domain, identified midpoint each domain, determine the midpoint between each data node, the number of node that are used to build content for all types of interpolation points in the region are executed instead the system must rebuild node for each interpolation point.

In this study, we use the RPIM were improve to simulate 2D linear elasto-static problems for isotropic and orthotropic 
functionally graded materials [FGM]. The method is applied to find numerical solution of several problems, the obtained results are compared with either analytical solutions or numerical solution form FEM that presented by other authors in the literatures [5], [6].

\section{MESHFREE RADIAL POINT} INTERPOLATION METHOD USING THIN PLATE SPLINE WEIGHT FUNCTION.

To approximate the distribution functions $\mathbf{u}\left(\mathbf{x}_{i}\right)$ within a sub-domain $\Omega_{x} \subseteq \Omega$, this function can be interpolated based on all nodal values at $\mathbf{x}_{i}$ within this sub-domain ( $\mathrm{i}=1, \ldots \ldots, \mathrm{n}$ and $n$ is the total number of nodes in the sub-domain). The well-known RPIM interpolation $x^{h}\left(\mathbf{x}_{i}\right)$, $\forall \mathrm{x} \in \Omega_{x}$ is frequently defined in the following form

$$
\begin{array}{r}
(u)^{\hat{h}}(\mathbf{x})=\sum_{i=1}^{n} R_{i}(r) a_{i}+\sum_{j=1}^{m} p_{j}(x) b_{j}= \\
=\mathbf{R}^{T} \mathbf{a}+\mathbf{P}^{T} \mathbf{b}=\left[\begin{array}{ll}
\mathbf{R}^{T} & \mathbf{P}^{T}
\end{array}\right]\left[\begin{array}{l}
\mathbf{a} \\
\mathbf{b}
\end{array}\right]
\end{array}
$$

Where $\mathbf{u}=\left[\begin{array}{llll}\mathbf{u}\left(\mathbf{x}_{1}\right) & \mathbf{u}\left(\mathbf{x}_{2}\right) & \ldots & \mathbf{u}\left(\mathbf{x}_{\mathbf{n}}\right)\end{array}\right]^{\mathrm{T}}$ is the vector of nodal displacements; $R_{i}(\mathrm{r})$ is the radial basis function; $p_{j}(x)$ is the monomial in the $2 \mathrm{D}$ space coordinates $\mathbf{x}^{T}=[x, y], j=1, \ldots \ldots, m$ where $\mathrm{m}$ is the number of polynomial basis functions. The constants $a_{i}$ and $b_{j}$ are determined to construct the shape function.

In this study, the radial basis functions used to construct the RPIM shape function are Thin Plate Spline (TPS) $R_{i}(r)=\eta^{n}$ with

$$
r_{1}=\sqrt{\left(x-x_{i}\right)^{2}+\left(y-y_{i}\right)^{2}} \text { the shape }
$$

parameter $\eta=4.01$ Enforcing $(u)^{h}(\mathbf{x})$ in equation (1) to pass through all the nodal values at $n$ nodes surrounding the point of interest $\mathbf{x}$, a system of $n$ linear equations are obtained, one for each node, which can be written in the matrix form as:

$$
\mathrm{U}_{s i}=\left[\begin{array}{llll}
u_{1} & u_{2} & \ldots & u_{n}
\end{array}\right]^{T}=\mathbf{R}_{0} \mathbf{a}+\mathbf{P}_{\mathrm{m}} \mathbf{b}
$$

The moment matrix of RBFs $\mathbf{R}_{0}$ and the polynomial moment matrix $\mathbf{P}_{\mathrm{m}}$ are as following

$$
\begin{aligned}
\mathbf{R}_{0} & =\left[\begin{array}{cccc}
R_{1}\left(n_{1}\right) & R_{2}\left(\eta_{1}\right) & \ldots & R_{n}\left(n_{1}\right) \\
R_{1}\left(\eta_{2}\right) & R_{1}\left(n_{2}\right) & \ldots & R_{1}\left(n_{2}\right) \\
\vdots & \vdots & \vdots & \vdots \\
R_{1}\left(\eta_{n}\right) & R_{1}\left(n_{n}\right) & \ldots & R_{1}\left(n_{n}\right)
\end{array}\right]_{n \times n} \\
\mathbf{P}_{m}^{T} & =\left[\begin{array}{cccc}
1 & \ldots & 1 \\
x_{1} & \cdots & x_{n} \\
y_{1} & \ldots & y_{n} \\
\vdots & \vdots & \vdots \\
P_{m}\left(x_{1}\right) & \ldots & P m\left(x_{n}\right)
\end{array}\right]_{m \times n}
\end{aligned}
$$

The vectors of coefficients for RBFs and the vector of coefficients for polynomial are

$$
\begin{aligned}
& \mathbf{a}^{T}=\left[\begin{array}{llll}
a_{1} & a_{2} & \ldots & a_{n}
\end{array}\right]^{T} \\
& \mathbf{b}^{T}=\left[\begin{array}{llll}
b_{1} & b_{2} & \ldots & b_{n}
\end{array}\right]^{T}
\end{aligned}
$$

There are $n+m$ variables in equation (2), so the following $m$ constraint conditions can be used as additional equations.

$$
\Sigma_{i=1}^{p} p_{j}\left(\mathbf{x}_{i}\right) a_{i}=\mathbf{P}_{m}^{T} a=0, j=1,2, \ldots, m
$$

Combining equations (2) and (7) yields the following matrix form

$$
\overline{\mathbf{U}}_{s d}=\left[\begin{array}{c}
\mathrm{U}_{s d} \\
0
\end{array}\right]=\left[\begin{array}{cc}
\mathbf{R}_{0} & \mathbf{P}_{\mathrm{m}} \\
\mathbf{P}_{m}^{f^{F}} & 0
\end{array}\right]\left[\begin{array}{l}
\mathbf{a} \\
\mathbf{b}
\end{array}\right]=\mathbf{G}_{0} \mathbf{a}_{0}
$$

The vector of coefficients $\mathbf{a}_{a}$ can be obtained by multiplying the inverted of matrix $\mathbf{G}_{0}$ with vector $\overline{\mathbf{U}}_{z A}$

$$
\mathbf{a}_{0}=\left[\begin{array}{l}
\mathbf{a} \\
\mathbf{b}
\end{array}\right]=\mathbf{G}_{0}^{-1} \overline{\mathbf{U}}_{s d}
$$

Substituting $\mathbf{a}_{0}$ to equation (1) can yield

$$
\left.(\mathrm{a})^{3} / \mathrm{x}\right)=\left[\begin{array}{ll}
\mathrm{R}^{T} & \mathrm{P}^{T}
\end{array}\right] \mathrm{G}_{0}^{-1} \overline{\mathrm{U}}_{s i}=\bar{\Phi}^{T}(\mathrm{x}) \overline{\mathrm{U}}_{s \bar{z}}
$$

where the RPIM shape functions can be express as:

$$
\begin{aligned}
& \bar{\Phi}^{T}(\mathbf{w})=\left[\begin{array}{ll}
\mathbf{R}^{T} & \mathbf{P}^{T}
\end{array}\right] \mathbf{G}_{0}^{-1}=
\end{aligned}
$$

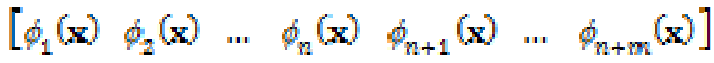

\section{Trang 132}


The vector of RPIM shape functions corresponding to the nodal displacements can be written as

$$
\boldsymbol{\Phi}^{T}(\mathrm{x})=\left[\begin{array}{llll}
\phi_{1}(\mathrm{x}) & \phi_{2}(\mathrm{x}) & \ldots & \phi_{\mathrm{n}}(\mathrm{x})
\end{array}\right]
$$

Finally, equation (10) can be rewritten as follows

$$
(u)^{h}(\mathrm{x})=\Phi^{T}(\mathrm{x}) \mathrm{u}_{s i}=\sum_{\mathrm{i}=1}^{n} \phi_{i} u_{i}
$$

One of the most important factors in meshless method is the concept of the influence domain and the radius of this domain that used to determine the number of field nodes within the interpolated domain of interest. Often, the size of support domain is computed with the following formula

$$
d_{g}=\alpha d_{z}
$$

Where $d_{\varepsilon}$ is the mean distance of the scattered node and $\alpha$ is the scaling factor.

\section{CONSTRUCTION OF SHAPE FUNCTIONS}

Let $\Omega$ be a bounded domain in R2 and consider the boundary value problem,

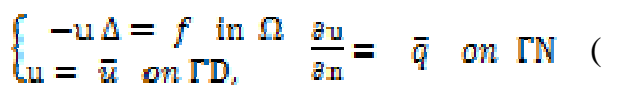

where $f$ is a field function given in $\Omega, \bar{u}$ is a Dirichlet condition given on $\Gamma D, \bar{q}$ is a Neumann condition given on $\Gamma \mathrm{N}$ and $\partial / \partial \mathrm{n}$ is differentiation along the outer normal to $\Gamma \mathrm{N}$.

We assume that $N$ field nodes, $\boldsymbol{x}_{i}, \ldots \ldots, \boldsymbol{x}_{n,}$ distributed in the problem domain and on its boundary are given. Consider an approximation of the solution $\mathrm{u}(\boldsymbol{x})$ represented as follows:

$$
u(x) \approx \sum_{i=1}^{N} u_{i} \phi_{i}(x)
$$

where $\phi_{i}(x)$ is a shape function corresponding to each field node $\boldsymbol{x}_{1}$. The purpose here is to determine the unknown coefficients, $u_{i}$, in (1), so that the approximate solution satisfies the boundary conditions. These coefficients can be obtained as the solution of the linear system,

$$
\begin{aligned}
& A\left[\begin{array}{lll}
u_{1} & \ldots & u_{N}
\end{array}\right]^{T}=\left[\begin{array}{lll}
y_{1} & \ldots & y_{N}
\end{array}\right]^{T} \\
& a_{i j}=\int_{n} \nabla \phi_{i}(x) . \nabla \phi_{j}(x) d x, y_{i}= \\
& \quad \int_{n} f(x) \phi_{i}(x) d x+\int_{\Gamma_{N}} \bar{q} \phi_{i}(x) d l
\end{aligned}
$$

After enforcement of the Dirichlet boundary condition. In this section, we suggest a new definition of the shape function in RPIM.

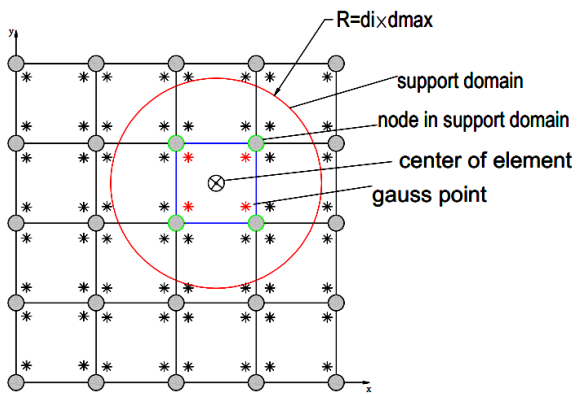

Figure 1. Support domain for RPIM shape function

In Fig.1 describe RPIM method, each domain supports constructed by a center and made a gauss point radius, $\mathbf{d}_{\max }$ is constant, $\mathbf{d}_{\mathbf{i}}$ is average cell size between the points, all of the nodes located the radius will be used building shape functions with gauss point that, so each time building a form for a function, there will be a loop is performed to determine the node point within a radius of gauss point.

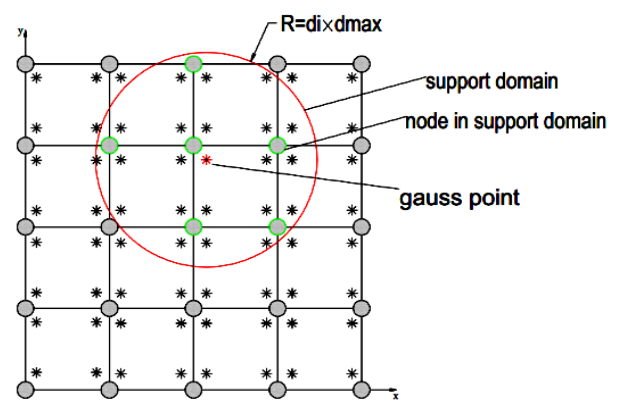

Figure 2. Support domain for improve RPIM shape function

In Fig. 2 describe improving RPIM, we set the midpoint between the elements, every midpoint is used to determine a support region, 
each gauss point of element which will use the identified node to build shape functions without having to run additional loop, this work helped reducing the loop as well as saving time.

\section{Numerical examples}

\subsection{Perforated tensile specimen}

Consider a plate with dimensions and boundary conditions as shown in Fig.3. The plate is subjected to a uniform tensile load at the top. The young modulus and Poisson ratio are given as $\mathrm{E}=$ $1 \mathrm{e} 3, v=0.3$. There are 210 nodes are used in this model.

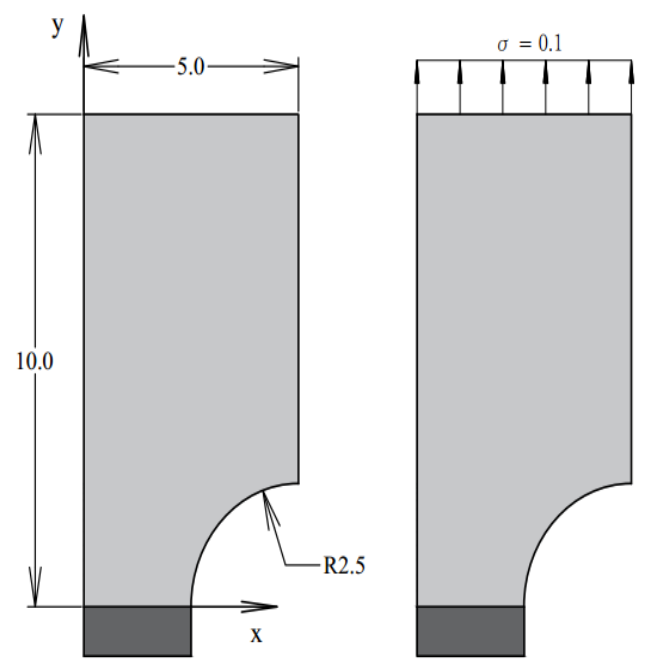

Figure 3. Profiles of plates.

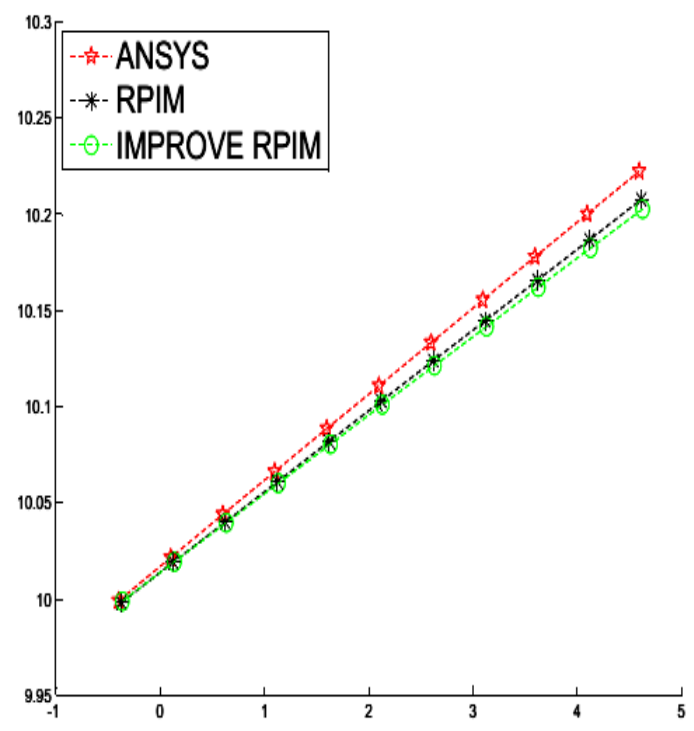

Figure 4. Position at the top edge
The positions at the top edge are displayed in Fig.4, the results obtained by improved RPIM are compared with FEM results given by Ansys and RPIM, indicating the error $<5 \%$ and results is acceptable.

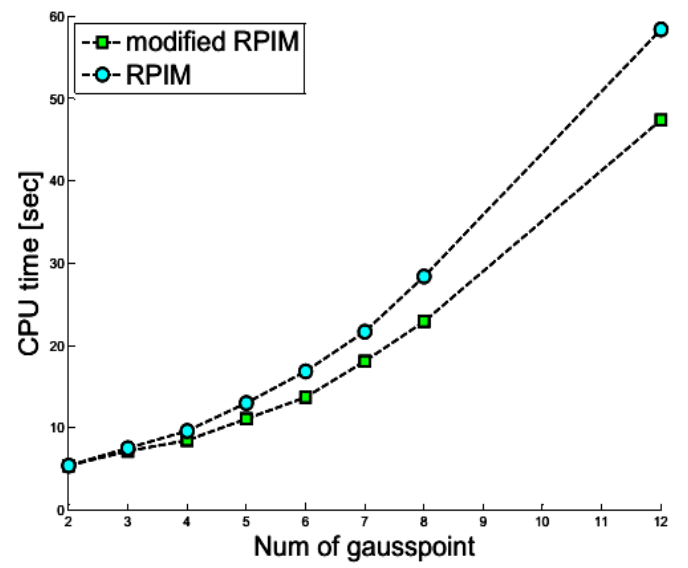

Figure 5. Compare CPU time.

Charts in Fig.5 show the comparison of CPU time in modified RPIM and traditional RPIM. It can be seen that modified RPIM gives result faster than RPIM. Especially in the case of using 12 Gauss point, the duration of modified RPIM faster 30s than RPIM.

\subsection{Plane stress bracket}

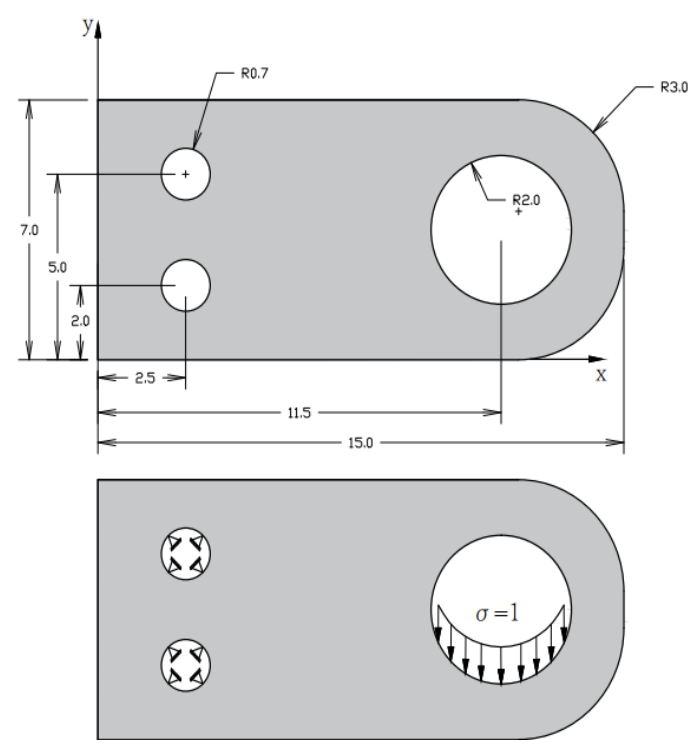

Figure 6. Profiles of plates. 


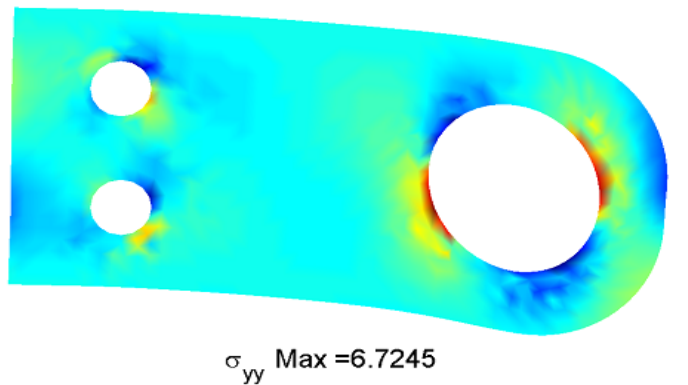

Figure 7. RPIM stress result $\sigma y y$.

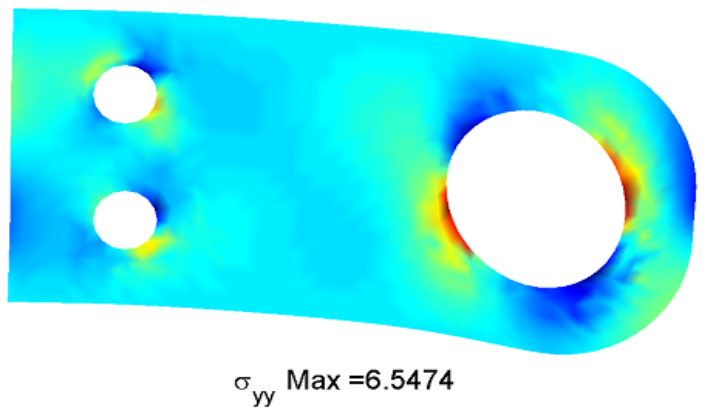

Figure 8. Improve RPIM stress result oyy.

Figure 7 and Figure 8 show the position and stress $\sigma y y$, results maximum stress in the $y$ direction, in this case the author uses 4 gauss point for an element, and the error is $2.63 \%$.

In this example, we consider a model with dimensions and Boundary conditions as shown in Fig.6. The plate is subjected to a uniform tensile load at the position of below edge of the bigger hole. The young modulus and Poisson ratio are given as $E=1 \mathrm{e} 3, v=0.3$. There are 1137 nodes are used in this model.

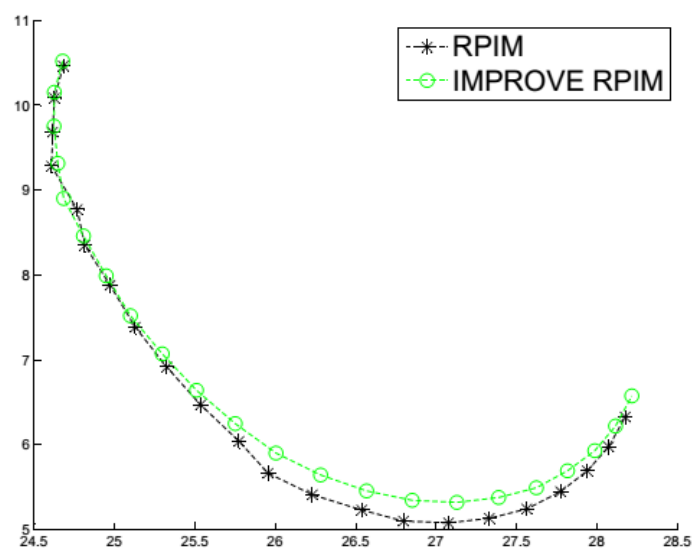

Figure 9. Position of below edge of the bigger hole, in this case 4 gauss points were used.

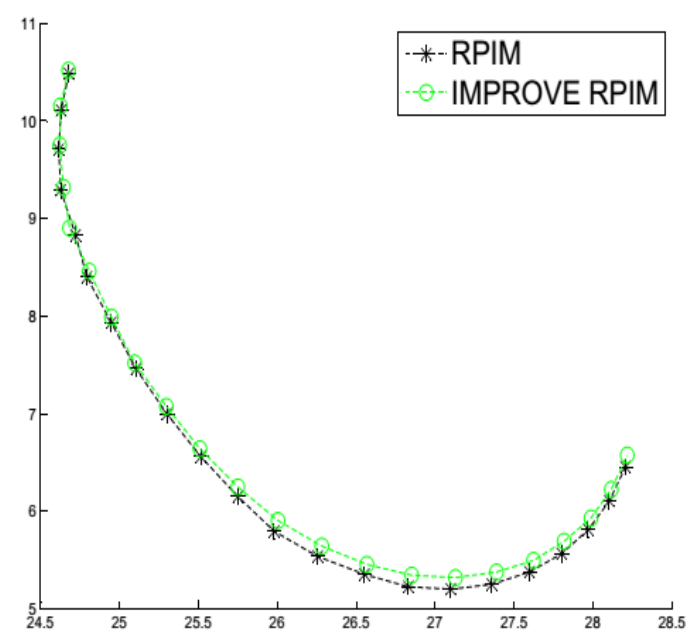

Figure 10. Position of below edge of the bigger hole, in this case 8 gauss points were used.

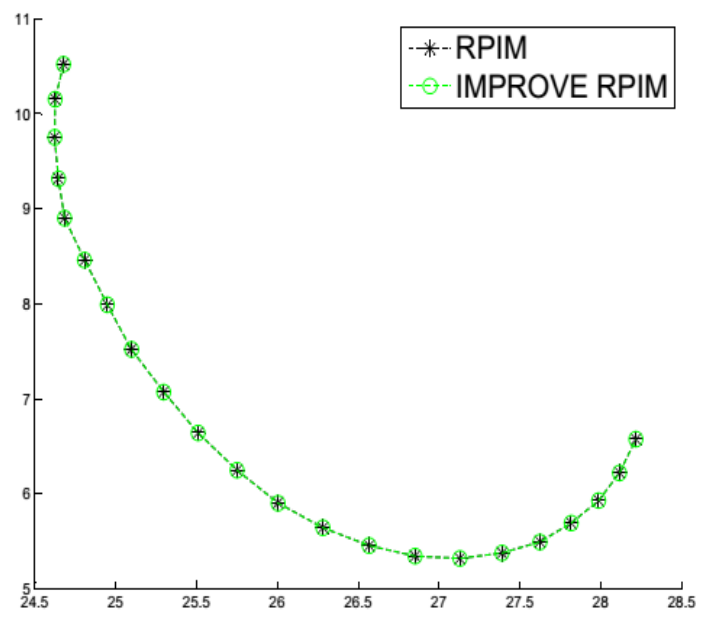

Figure 11. Position of below edge of the bigger hole, in this case 12 gauss points were used.

Plots in Fig.9, Fig.10 and Fig.11 show the position below edged of the bigger hole. It can be seen that resulting in displacement of RPIM and modified RPIM as asymptotic when gauss points ascending score, in this case the author uses 4, 8 , 12 gauss points, use cases 12 gauss point results of the two methods for error close to zero.

\subsection{Isotropic FGM link bar}

The FG link bar, made of titanium/titanium monoboride is subjected to a tensile load of 1 unit at the right edge. Values assigned to material parameters of titanium monoboride (TiB) and titanium $(\mathrm{Ti})$ are 
$E_{\text {TiE }}=375 \mathrm{Gpa}$

$E_{T i}=107 \mathrm{Gpa}, \theta_{T \mathrm{i}}=0.34$

These properties are assumed to vary exponentially in the y-direction according to the following relations:

$$
\begin{aligned}
& E(y)=E_{T i} e^{\beta_{E} y} \\
& \theta(y)=\theta_{T i} \theta^{\beta_{y} y}
\end{aligned}
$$

where the non-homogeneity parameters $\beta_{E}$ and $\beta_{\theta}$ are given by

$$
\beta_{E}=\frac{1}{W} \log \left(E_{T i E} / E_{T i}\right)
$$

$$
\beta_{0}=\frac{1}{w} \log \left(\theta_{T i v} / \theta_{T i}\right)
$$

In Fig.13 authors used modified RPIM to calculate the FGM, maximum stress in the directions $x$ at location I and II (5th row in Table 1 left) is compared with the results of other articles [10], [11], [12], error when using RPIMmodified with FGM were compared with RBFMLPG5 at location I is $1.62 \%$ and $2.37 \%$ at location II.

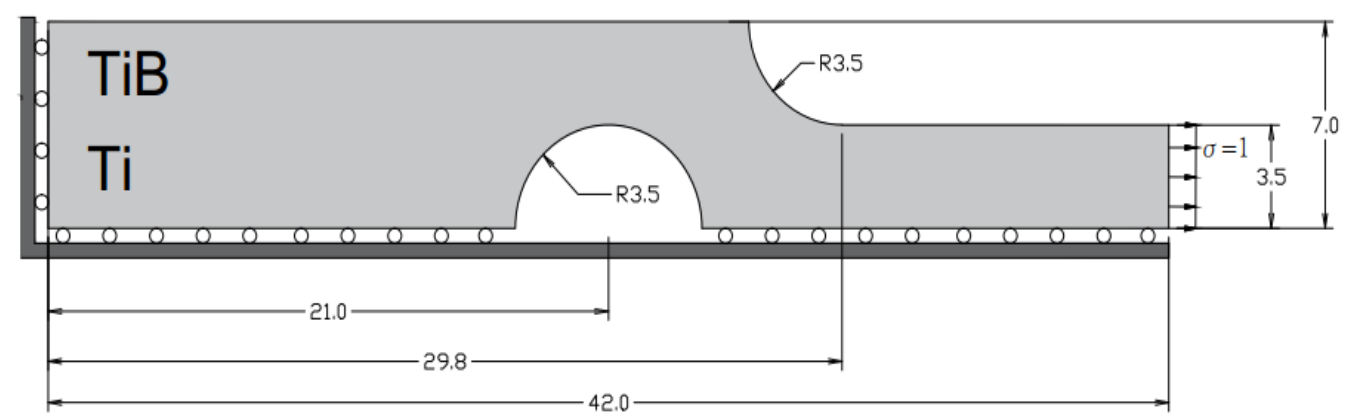

Figure 12. Profiles of plates with functionally graded materials (FGM) was used.

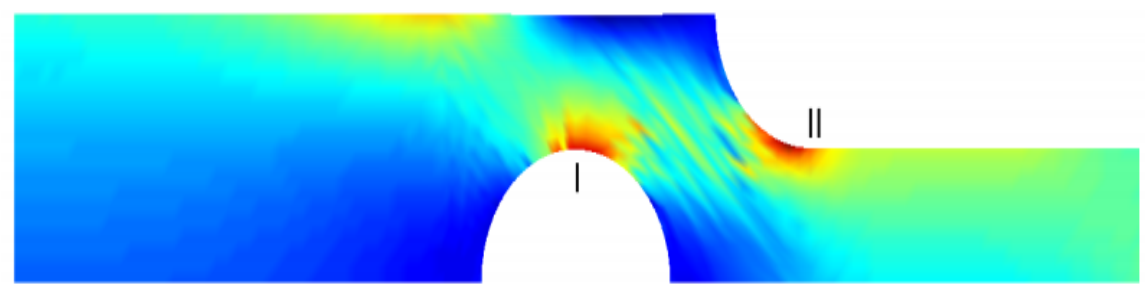

Figure 13. Improve RPIM stress result $\sigma x x$ with FGM.

Table 1. Comparison of normal stress in the direction $\mathrm{x}$.

\begin{tabular}{|l|l|l|l|}
\hline \multicolumn{1}{|c|}{ Method } & Material property & Location I & Location II \\
\hline \multirow{2}{*}{ FEM(Graded element) [10] } & Homogeneous & 2.908 & 2.137 \\
\cline { 2 - 4 } & FGM & 2.369 & 2.601 \\
\hline \multirow{2}{*}{ MLS-MLPG1 [11] } & Homogeneous & 2.918 & 2.140 \\
\cline { 2 - 5 } & FGM & 2.360 & 2.594 \\
\hline RBF-MLPG5 [12] & Homogeneous & 2.901 & 2.131 \\
\cline { 2 - 5 } & FGM & 2.403 & 2.607 \\
\hline \multirow{2}{*}{ RPIM-modified } & Homogeneous & 2.937 & 2.153 \\
\cline { 2 - 5 } & FGM & 2.364 & 2.669 \\
\hline
\end{tabular}

\section{Trang 136}




\section{CONCLUSION}

The work has now developed an effective algorithm based on radial meshfree method of interpolation points. In this method, the shape functions are determined depending on the subdomain is considered a part of a rectangle bounds of the problem domain. The new definition allows us to quickly assess the function of the form from the matrix to assess functional shape and form of their decomposition can be calculated in advance of the pre-treatment evaluation process. Our numerical results indicate that the new definition of the shape functions provide reliable solutions with low computational cost. In addition, the results showed that the new definition contributes to rapid assessment of the approximate solution.

\section{Cải thiện phương pháp không lưới RPIM và áp dụng phân tích ứng xử đàn hồi cho vật liệu phân lớp chức năng FGM.}

- Phùng Quốc Việt

- Nguyễn Thanh Nhã

- Trương Tích Thiện

Trường Đại học Bách khoa, ĐHQG-HCM

\section{TÓM TÁ́T:}

Phương pháp không lưới dựa trên phương pháp nội suy điểm qua tâm (RPIM) gần đây được phát triển như một công cụ hiệu quả để giải phương trình vi phân từng phần và được áp dụng rộng rãi để giải quyết các vấn đề khác nhau. Ngoài những ưu điểm vược trội của nó, trong bài viết này chúng tôi giới thiệu một chương trình tính mới nhằm cải thiện tốc độ cũng như là thời gian tính toán, bằng việc xây dựng và thẩm định lại các miền hố trợ. Tì̛ việc phân tích hai chiều các tấm mỏng có biên dạng khác nhau, có cấu trúc vật liệu đẳng hướng thông thường và vật liệu phân lớp chức năng (FGM), kết quả sẽ được so sánh với những bài toán đã thực hiện trước đây: một mặt cho thấy tính chính xác khi sử dung chương trình mói, mặt khác cho thấy thời gian tính là tiết kiệm hơn.

Từ khóa: Phương pháp không lưới, Hàm cơ sở hướng kính, Phép nội suy điểm hướng kính, FGM. 


\section{REFERENCES}

[1]. T. Belytschko, Y. Y. Lu and L. Gu, Element-Free Galerkin Methods, International Journal for Numerical Methods in Engineering, Vol. 37, Issue 2, 229-256 (1994).

[2]. P. Lancaster and K. Salkauskas, Surfaces

Generated by Moving Least Squares Methods, Mathematics of Computation, Vol. 37, 141-158 (1981).

[3]. G. R. Liu, Mesh free methods: moving beyond the finite element method, CRC Press, Boca Raton (2002).

[4]. J. G. Wang and G. R. Liu, A point interpolation meshless method based on radial basis functions, International Journal for Numerical Methods in Engineering, Vol. 54, Issue 11, 1623-1648 (2002).

[5]. Nguyen Thanh Nha ${ }^{1}$, Nguyen Thai Hien ${ }^{2}$, Bui Quoc Tinh ${ }^{3}$, Truong Tich Thien ${ }^{4}$, Meshfree radial point interpolation method for elastostatic analysis of isotropic and orthotropic functionally graded structures, 09/04/2014.

[6]. L.S. Miers, J.C.F. Telles, Two-dimensiona 1 elastostatic analysis of FGMs via BEFM, Received 3 March 2007; accepted 23 March 2007 Available online 4 February 2008.

[7]. T. Mori, K. Tanaka, Acta Metall. 21 (1973) 571-574.

[8]. R. Hill, J. Mech. Phys. Solids 13 (1965) 213-222.

[9]. Kim J. H., Paulino G. H. - Isoparametric Grade Finite Elements for Nonhomogeneous Isotropic and Orthotropic Materials, Appl. Mech. 69 (2002) pp. 502-514.

[10].Kim J. H., Paulino G. H. - Isoparametric Grade Finite Elements for Nonhomogeneous Isotropic and Orthotropic Materials, Appl. Mech. 69 (2002) pp. 502-514.

[11].Ching H. K., Yen S. C., Composites B 36 (2005) 223-240.

[12].Gilhooley D.F. et al - Two-dimensional stress analysis of functionally graded solids using the MLPG method with radial basis functions, Computational Materials Science 41 (2008) 467-481. 